\title{
High hopes for Astro-1
}

\section{Washington}

IN 1978, when the space shuttle was being advertised as a regular bus service into Earth orbit, the National Aeronautics and Space Administration (NASA) invited scientists to propose instrumental payloads that could be flown repeatedly, once or twice a year, making the shuttle into an easily used space science platform. But it has taken 12 years for the first of those proposals, a set of astronomical telescopes known as Astro-1, to get off the ground. And the future of Astro, due to have been launched yesterday, 30 May, is far from guaranteed. No additional missions are scheduled, and only after this first flight has been evaluated will NASA decide whether the instruments, tailor-made for the shuttle, will be used again.

Astro-1 consists of two separate astronomical packages which find themselves on the same flight because of the disruption caused by the 1986 Challenger explosion. The larger part of Astro-1 is a set of three ultraviolet telescopes - an imager, a spectrophotometer and a polarimeter that was to have flown in early 1986 , along with a camera specially designed to photograph Comet Halley. When shuttle flights resumed three years later, Halley was long gone, and instead of the camera the Broad-Band X-ray Telescope (BBXRT) was mounted alongside. BBXRT was originally part of an X-ray astronomy package, but was pulled out and made ready earlier in order to take X-ray pictures of supernova 1987A.

The two parts of the Astro-1 package are on separately steerable mounts attached to pallets inside the cargo bay. As the shuttle pilot holds the craft for several hours in a fixed attitude, other crew members point the telescopes at a series of predetermined target stars. All three ultraviolet instruments - the Hopkins Ultraviolet Telescope (HUT), the Ultraviolet Imaging Telescope (UIT) and the Wisconsin Ultraviolet Photo-Polarimeter Experiment (WUPPE) - are aligned together and observe the same object, and for about 20 per cent of the planned observations BBXRT will also be pointed in the same direction to provide simultaneous X-ray imaging. Both ultraviolet and $\mathrm{X}$-ray astronomy specialize in energetic cosmic phenomena: young stars, supernova remnants, quasars and hot interstellar gas.

With the exception of UIT, which takes photographs that will be developed on the ground, the Astro-1 instruments will send down data in real-time, allowing astronomers at Marshall Space Flight Center in Alabama to re-adjust the observing program should some transient phenomenon such as an X-ray binary or a cataclysmic variable erupt. According to Peter
Serlemitsos, BBXR' project investigator, the enforced hiatus caused by the Challenger accident has allowed mission controllers to become much more comfortable with last-minute schedule changes.

In the weeks following the ten-day mission, astronomers will be more than usually anxious to see what their search of the sky has trawled up. Although NASA has promised money to support maintenance and even some further development of the Astro-1 hardware, according to HUT co-investigator Knox Long, no commitment even in principle to another launch has been made. Both Long and
Serlemitsos are expecting NASA to evaluate Astro-1 later this year, with the payloads being kept in storage at the Kennedy Space Center until, as Long puts it, "the situation clarifies". Another mission could be put together at about six months' notice, provided everything works as planned, but the nearest hint of an open slot in the shuttle manifest, says Serlemitsos, is not until 1993.

The possibility of avoiding these problems by making the two parts of the Astro mission into self-contained satellite observatories, needing the shuttle neither for launch nor for operation, is now almost gone. Astro-1 may have to do spectacularly well to avoid premature consignment to a museum.

David Lindley

\section{Pot of gold sought in the East}

\section{Washington}

ARMED with little more than a letter from President Bush and a blueprint, a US Department of Energy (DOE) team departs for Japan and Korea this week to find partners for the Superconducting Super Collider (SSC).

Although DOE officials do not expect to come back with any contracts, they do hope to start work on government-level collaboration agreements. However, what DOE is willing to offer in exchange for money or equipment remains a 'classified' secret. Some Japanese researchers have expressed interest in the project, but the government of Japan has sent few public signals of encouragement.

DOE officials have previously indicated that the international foray would begin as soon as a final cost estimate for the $20 \mathrm{TeV}$ proton accelerator had been set. But as DOE deputy secretary W. Henson Moore and other DOE and White House officials prepared to leave last week, that price was still only a guess of around $\$ 8,000$ million.

Congress recently passed legislation demanding that one-third of the project's cost come from non-federal sources. The state of Texas has promised $\$ 1,000$ million, leaving DOE still to find an additional $\$ 1,600$ million or so elsewhere. So far, the only definite international promise had been $\$ 50$ million from India, but even that appears to have gone soft. "We are not sure how solid any of those past commitments are. We're treating them all as tentative", Moore said.

Whether DOE will allow foreign partners to make the more sophisticated components of the accelerator - to the advantage of their high-tech industries remains an open question. Congress has stressed that technological manufacturing, particularly of the SSC's superconducting magnets, should remain at home (for some politicians, technology spin-offs remain the project's chief selling point). Moore announced that the contract for the magnets is now up for grabs, and both US and international companies may apply. But whether Japan will be given a real chance at the contract as part of a collaboration deal is not known.

DOE officials plan to extend their search for partners to Europe in October. By then they also hope to have named a director for the project at DOE headquarters and to have settled on a final price.

G. Christopher Anderson

Tokyo

Yubun Narita, director of scientific affairs at the Japanese Ministry of Foreign Affairs, says that the meeting will be the first detailed explanation of the project by US government officials, and as such Japan cannot make any commitments at this stage. Only after hearing the US explanations and requests for help will Japan decide what (if anything) to do next.

The views of Japanese high-energy physicists on the SSC are divided. Some researchers at the High Energy Physics Laboratory (KEK) in Tsukuba are keen to participate in the experimental phase of the programme. But others in the Universities would prefer to collaborate with the European Laboratory for Particle Physics (CERN) in the operation of CERN's proposed Large Hadron Collider because participation in that (if it goes ahead) is expected to be cheaper.

At present, there seems to be little support among the Japanese scientific community for Japan to contribute to the construction costs of the SSC. One physicist at KEK asks "What is the point if they don't want our superconducting magnets? Would our contribution be some form of ODA (Overseas Development Assistance)?"

David Swinbanks 